\title{
الحروب على البيئة الطبيعية من منظور القانون الدولي
}

\author{
خديجة بركاني \\ كلية الحقوق \\ جامعة باجي مختار _عنابة
}

لطالما شكلت البيئة الطبيعية بمختلف عناصرها عاملا

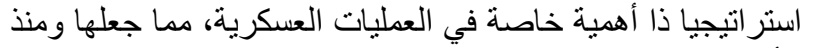

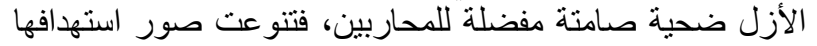

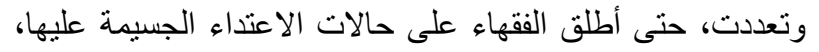

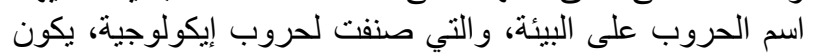

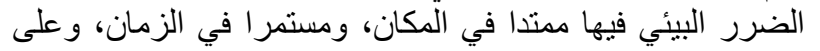

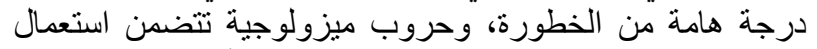

تقنيات تغيير جيوفيزيائية ومناخية لتحقيق أغرواض وحروبة عسكرية

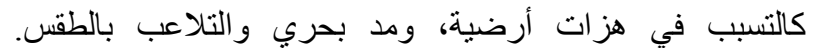

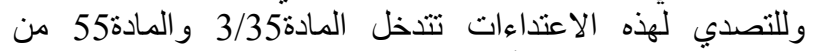

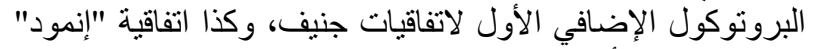

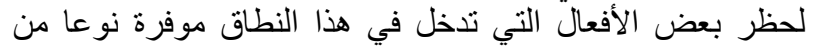

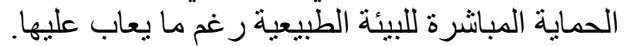

الكلمات المفتاحية: حرب بيئية، حرب ميزولية للئية مابية، حماية مباشرة.

\section{Abstract:}

The natural environment has always constituted, with these different elements, a strategic factor in the military operations, which made it since the eternity the privileged silent victim of the combatants. And as the forms of attacks continue to multiply, some lawyers prefer to call the most severe attacks of them: wars against the environment, and classify them into two categories: ecological war where environmental damage is widespread, long-term and sever , and mesological warfare involving geophysical and climatic modification techniques for military purposes such as earthquake or tsunami provocation or meteorological manipulation. In order to deal with these violations, Article $35 / 3$ and Article 55 of the First Additional Protocol to the Geneva Conventions, as well as the ENMOD Convention, prohibit certain acts in relation, thus providing a kind of direct protection to the natural environment despite their shortcomings 


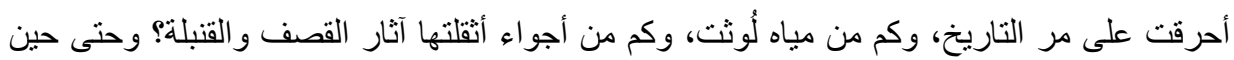

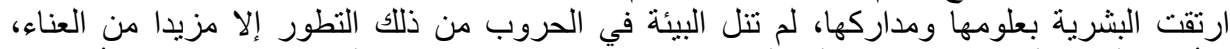

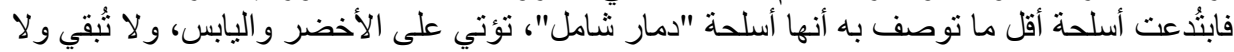

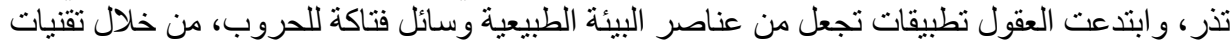

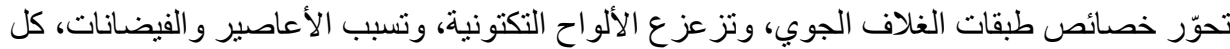

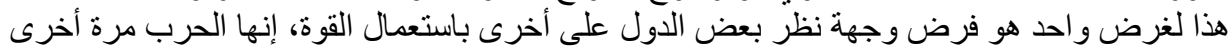

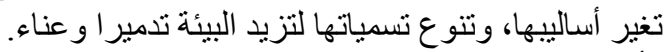

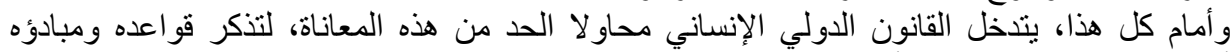

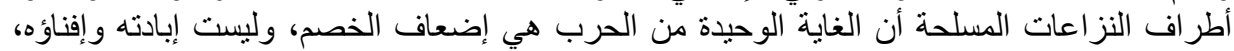

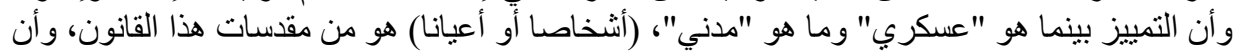

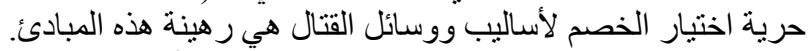

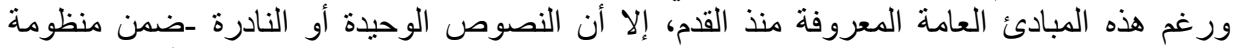

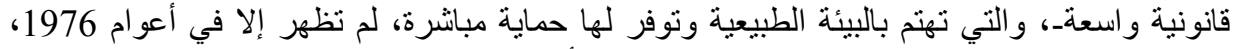

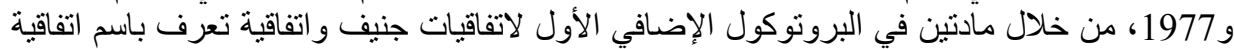

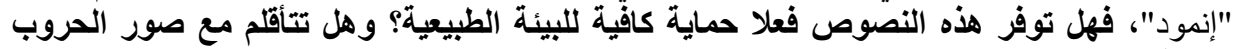

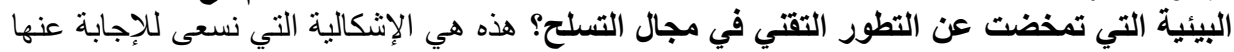

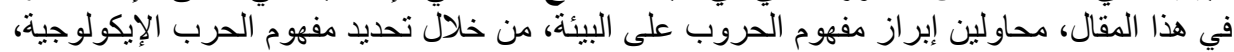
والحروب الميزولوجية، ثم البحث في النصوص التي التي تحاول التصدي لها أو على الأقل التقليل من الإكن ويلاتها.

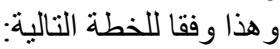
المبحث الأول: مفهوم الحروالئ: المروب على البيئة المطلب الأول: الحرب: مفرم الإيكولوجية المبلية المطلب الثاني: الحرب الحرب الميزولوبكولية

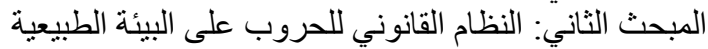

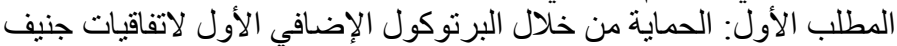

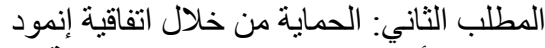

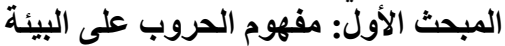

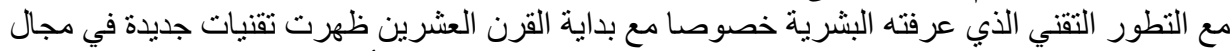

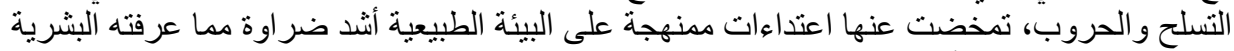

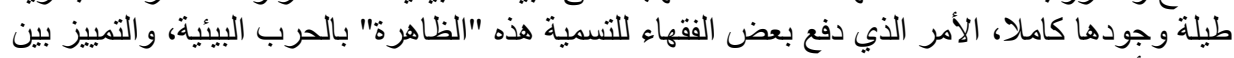

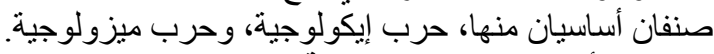

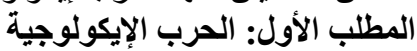
الحرب الإيكولوجية تلعني استهدافيا منظما لعناصية العناصر البيئة الطبيعية، باستعمال وسائل أو أساليب يحظر ها

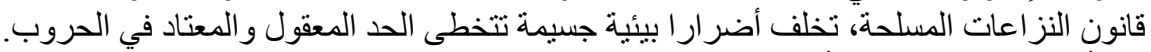

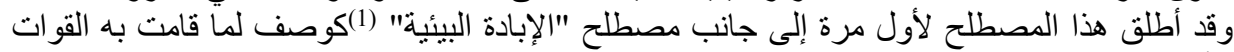

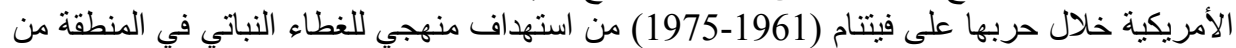

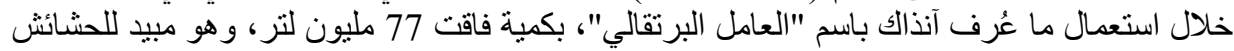

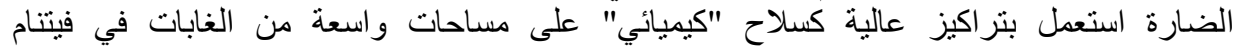

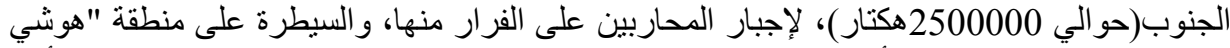

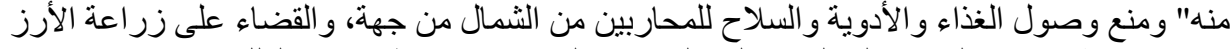

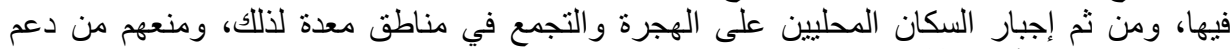
المقاومة من جهة أخرى(2). 
ونتج عن الرش الكثيف للعامل البرتقالي في الغابات الاستوائية في المنطقة لآثار واضطر اباتات خطيرة

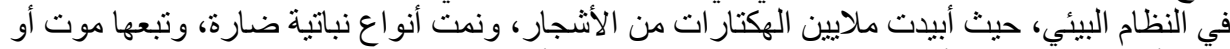

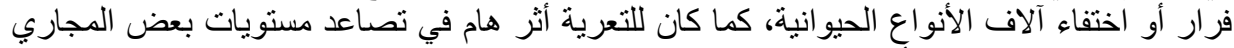

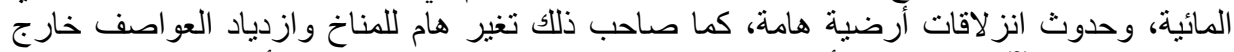

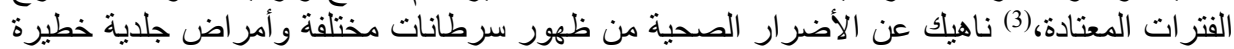
وتز ايد نسب التشو هات الجنينية لأكثر من ثناث الجنأ أجيال متنالية.

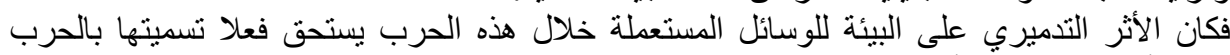
البيئية أو الإيكولوجية، أو حتى الإبادة البيئية.

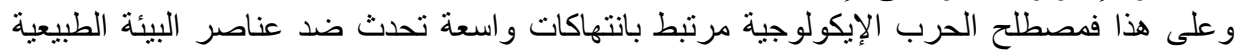

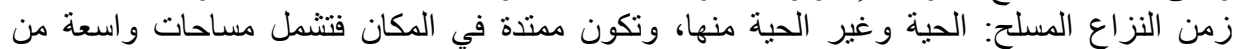

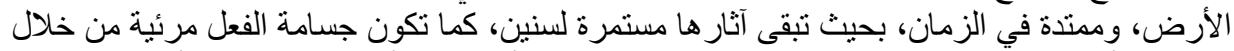
جسامة الأضرار التي تلحق بالعناصر الطبيعية، بتدمير ها أو تلوثها أو القضاء القضاء عليها أو الإسهام في الانتقاص من نو عيتها(تدهور هان).

ويمكن أن تتحقق الحرب الإيكولوجية باستعمال أسلحة تقليدية، لكنها أكثر نوقعا باستعمال أسلحة دمار

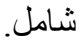

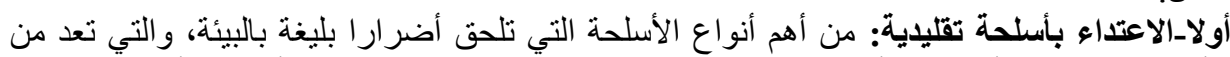

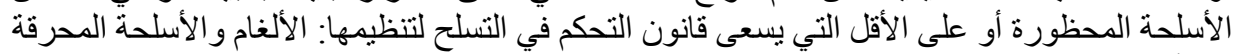

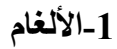

تعرف المادة 2 من البروتوكول الثاني الملحق باتفاقية الأسلحة التقليدية والمتعلق بحظر أو تقييد

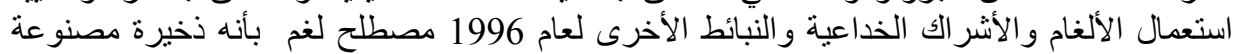

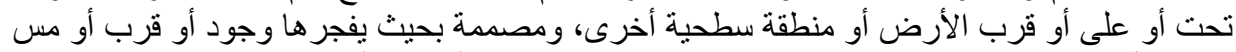

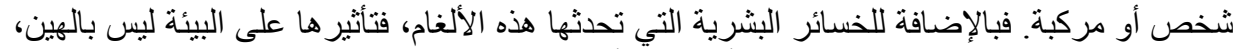

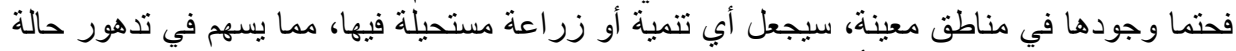

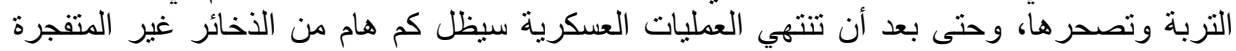

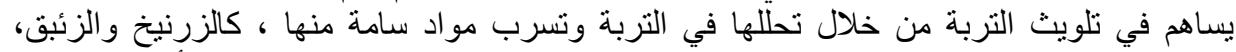

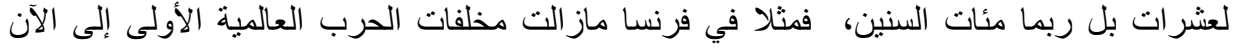

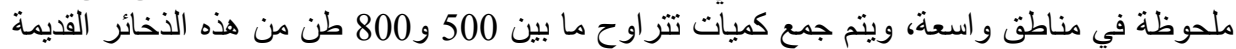

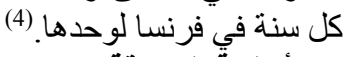

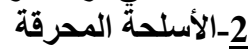

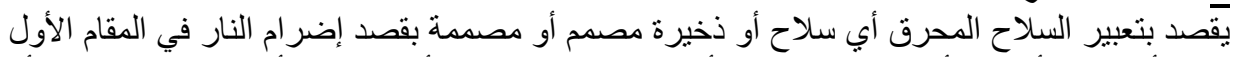

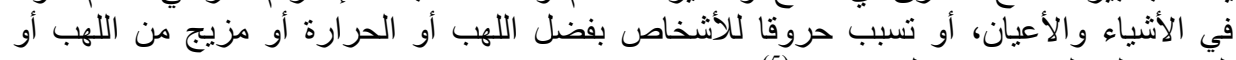

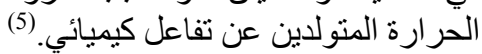

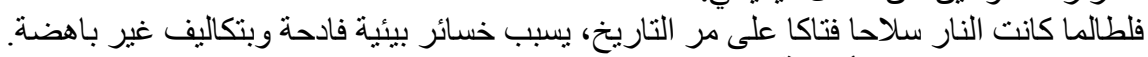

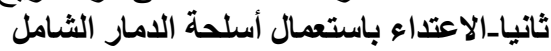

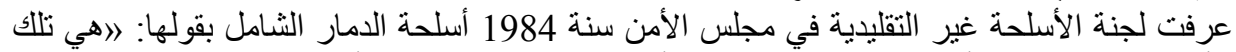

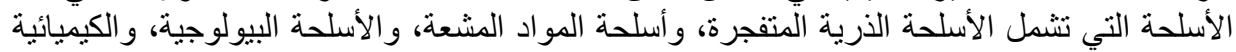

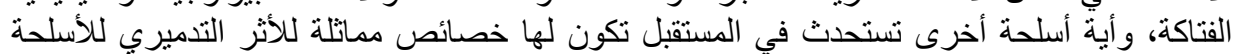

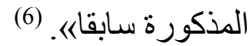

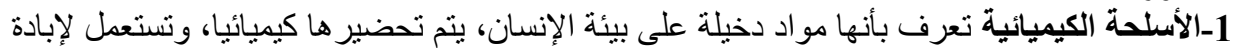

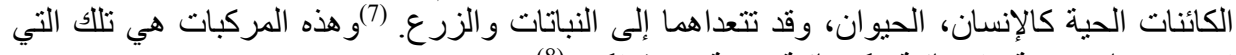

تجمع صفات سمية وفيزيائية وكيميائية معينة بحيث تكون الإنى النيات 
ـسميتها عالية رغم استعمال كميات ضئيلة منها، يمكن تصنيع كميات ضخمة منها، تتمتع بالاستقرار

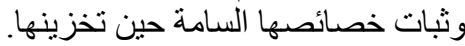

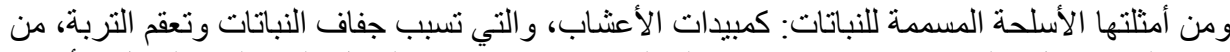

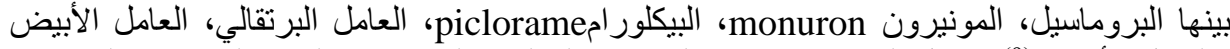

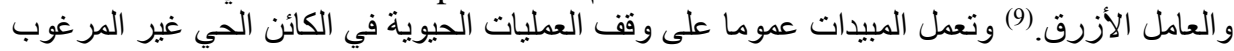

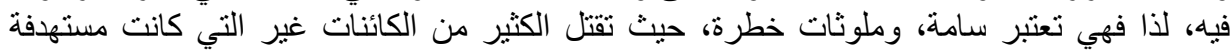

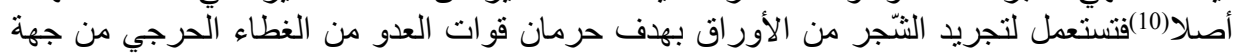

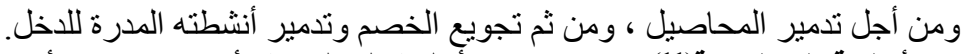

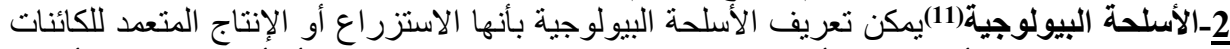

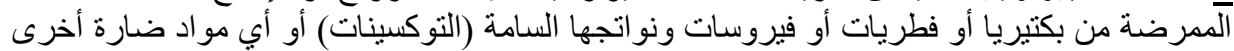

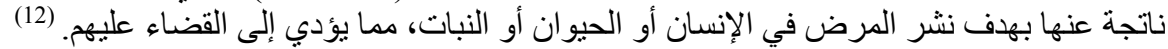

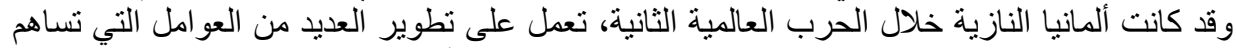

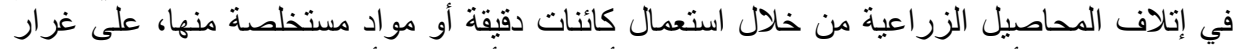

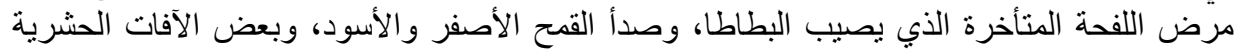

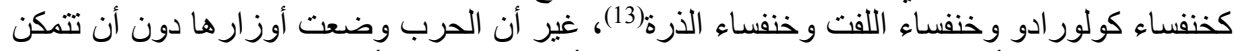

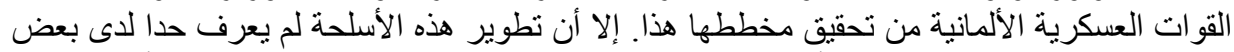

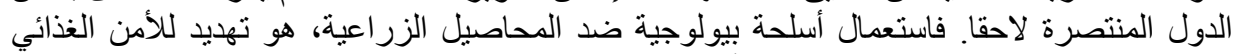

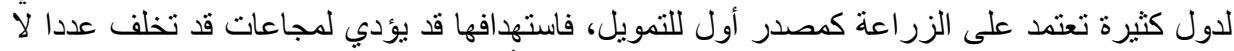

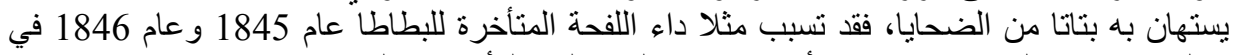

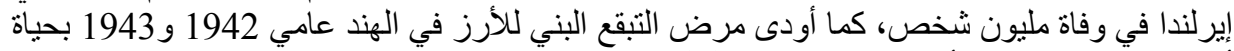

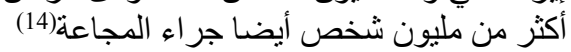
3-الأسلحة النووية: وتعرف الأسلحة النورية بأنها آلة حرب ذات ذات طاقة تدميرية تفجيرية هائلة،

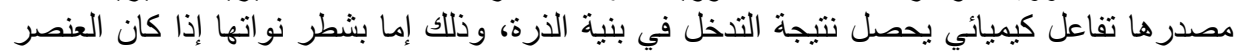

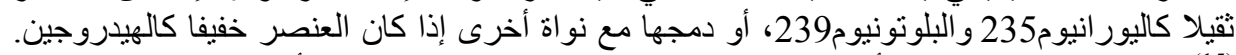

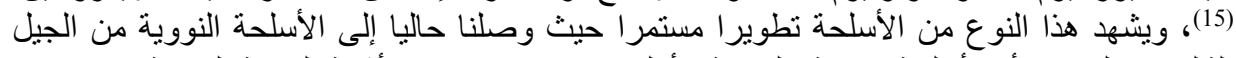

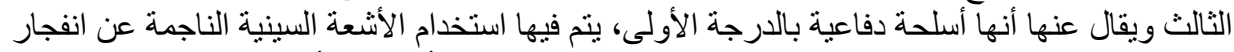

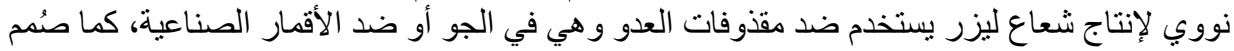

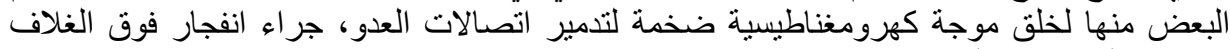

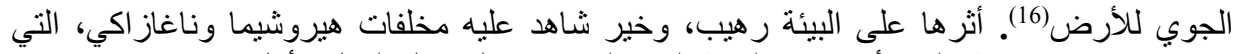

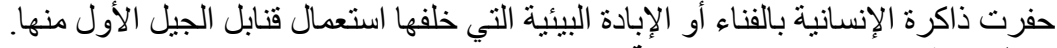

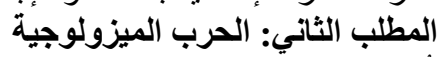

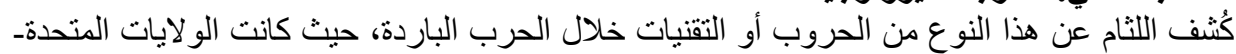

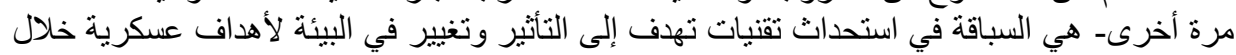

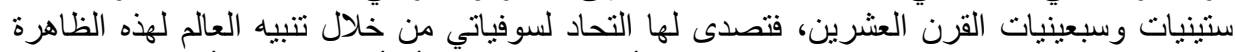

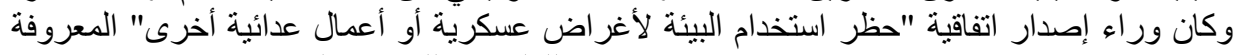

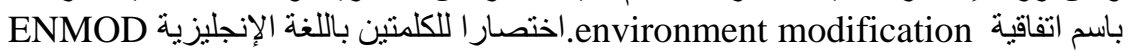
وقد أوضحت المادة الثانية من الاتفاقية المقصود بعبارة تقنيات التغيير في البيئة: أية تقنية لإحداث

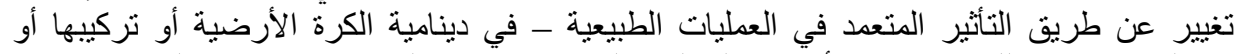

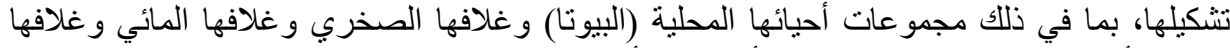

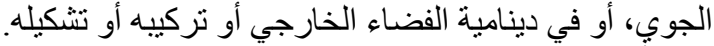

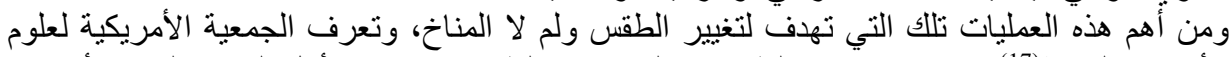
الأرصاد الجوية(17)، كلا من "تغيير الطقس" والتحكم في الطقس" فتعني بالأول التغيير العدي وني أو غير التهري 


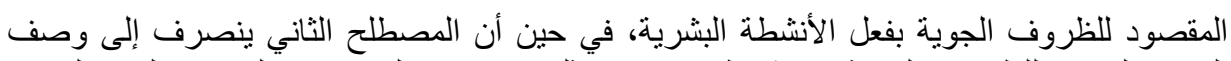

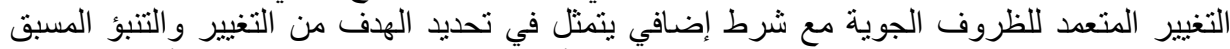

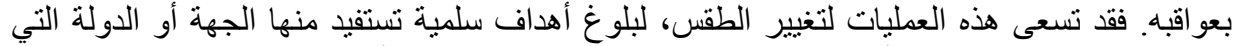

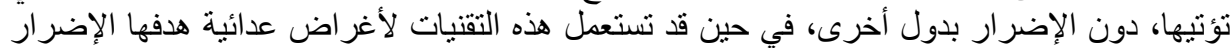

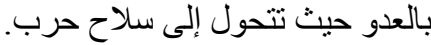
بحيث تسعى برامج البحث في هذا المجال إلى تغيير الظو اهر الجوية على مساحة محدودة ولمدة زمنية

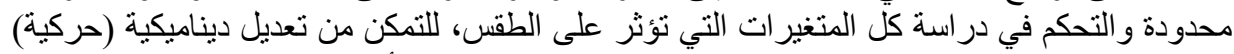

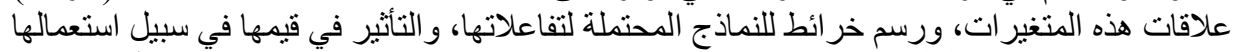

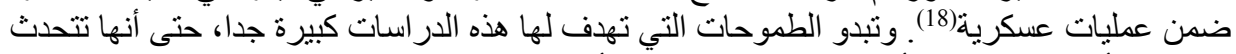

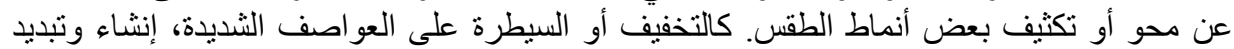

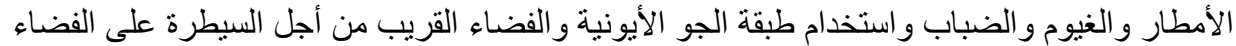

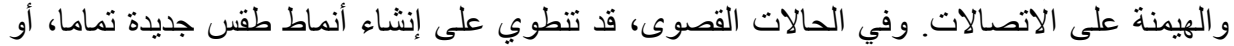

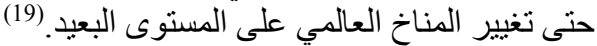

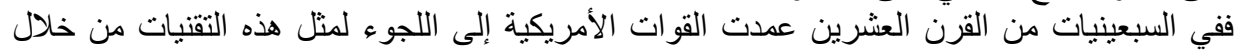

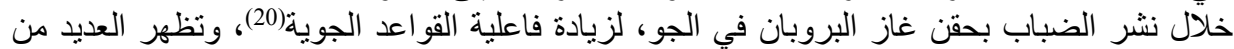

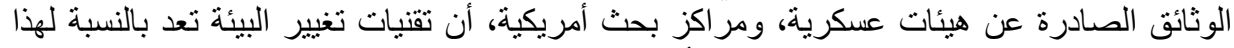

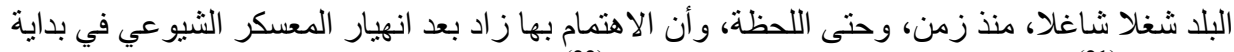

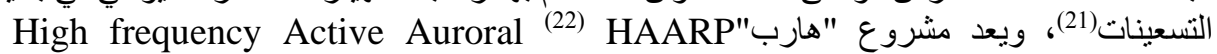

Research Program

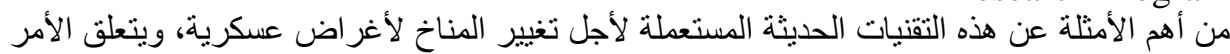

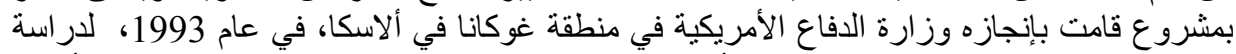

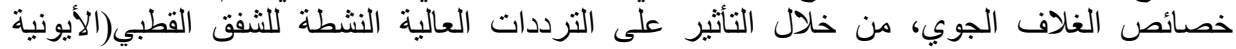

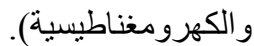

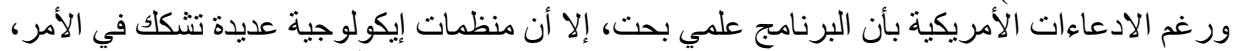

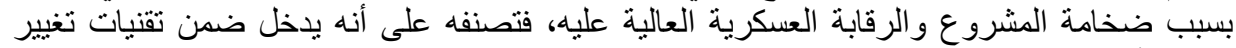

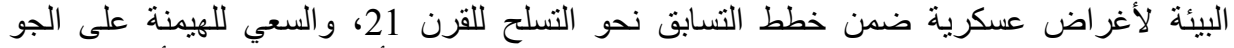

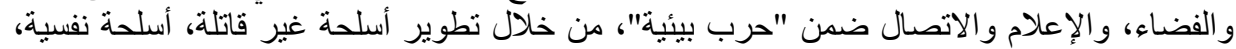

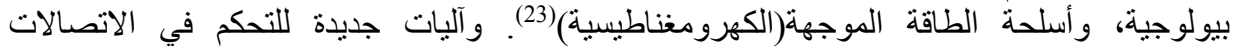

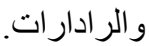

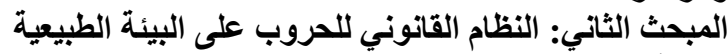

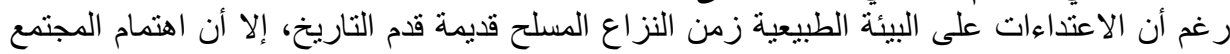

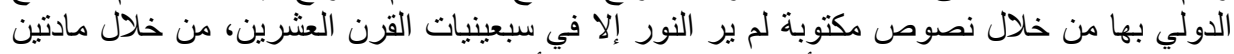

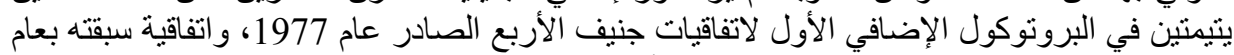

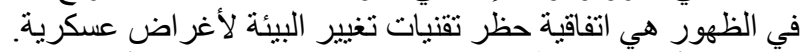

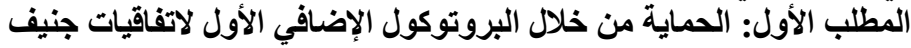

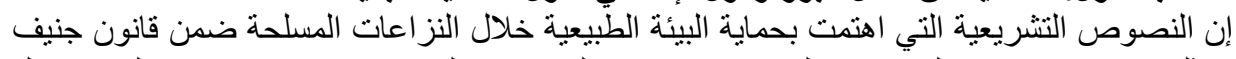

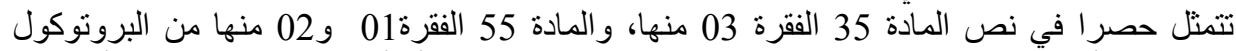

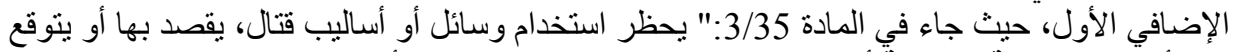

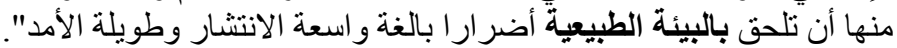

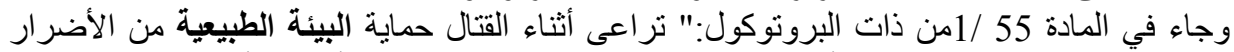
البالغة واسعة الانتشار وطويلة الأمد، وتتضمن هذه الحماية حظر استخدام أساليب أو وسائل القتال التي التي 
يقصد بها أو يتوقع منها أن تسبب مثل هذه الأضرار بالبيئة الطبيعية ومن ثم تضر بصحة أو بقاء

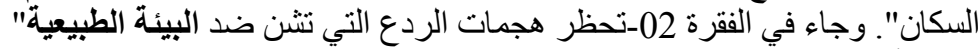

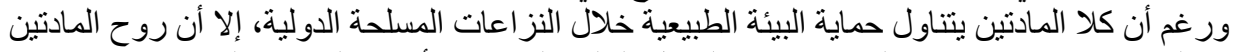

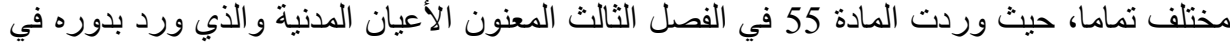

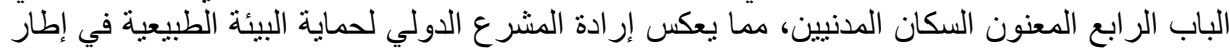

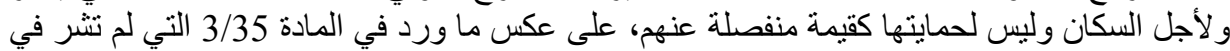

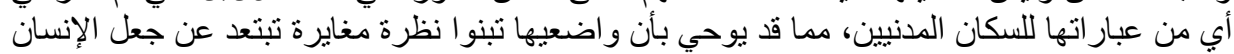
محور الحماية، وتحمي البيئة الطبيعية لذاتها.

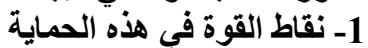

لـعل أهم نقطة تحتسب للحماية الواردة في نص المادتين3/35 و المادة 55 من البروتوكول الأول تتمثل

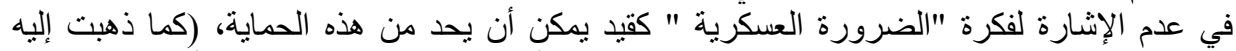

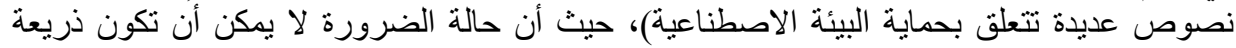

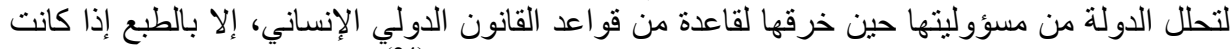

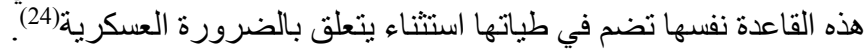

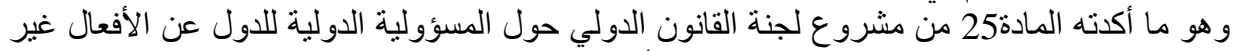

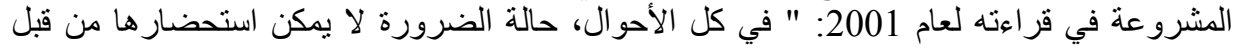

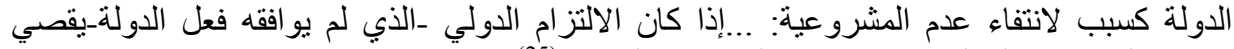

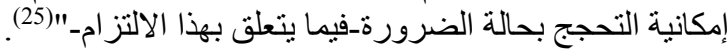

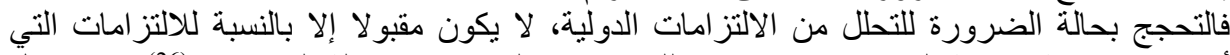

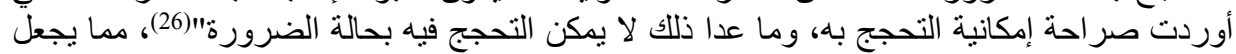

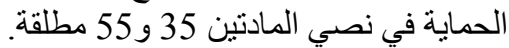
ـكما أن مجال الحماية واسع، حيث تحظر المانئ وادتان استعمال أي وسيلة أو أسلوب يسبب أضرارا بالبيئة

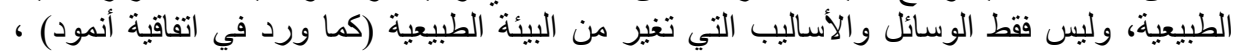

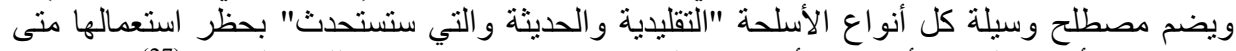

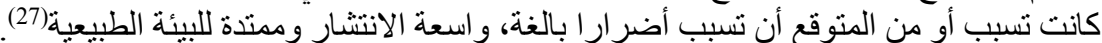

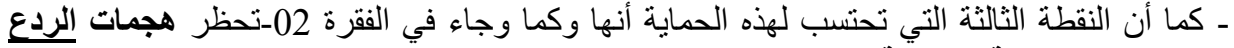

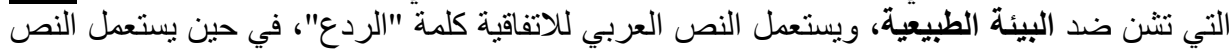

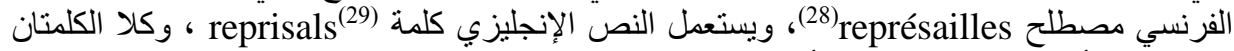

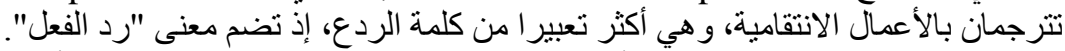

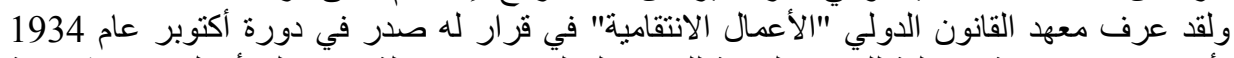

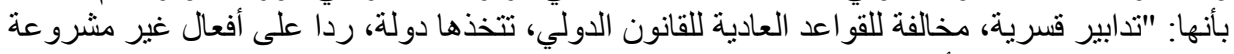

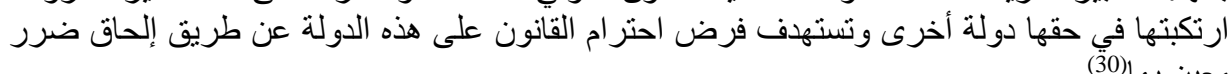

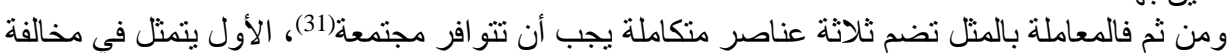

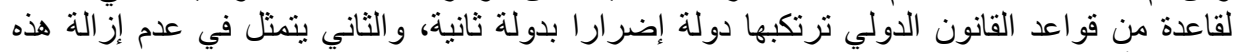

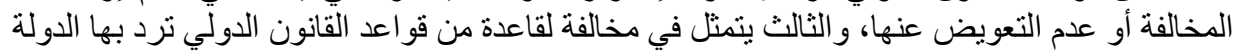

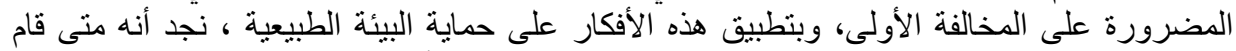

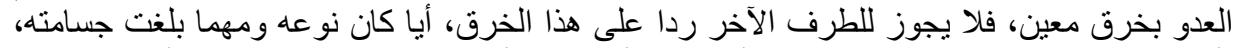

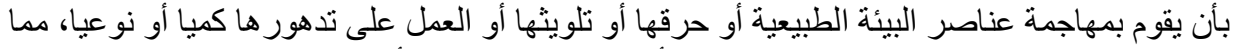

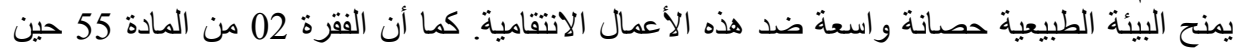

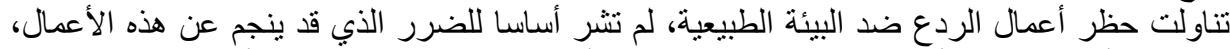

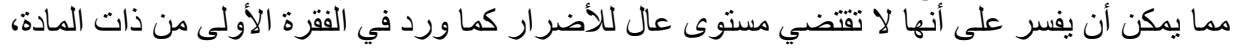


يخلفها يعني أن كل عمل ردع أو انتقام ضد البيئة الطبيعية محظور، مهما صغر أو كبر الضرر الذي -و النقطة الأخيرة التي يمكن احتسابها في هذا الججال تتعلق بفكرة شبيهة ، تتمثل في الالتزامات التبادلية،

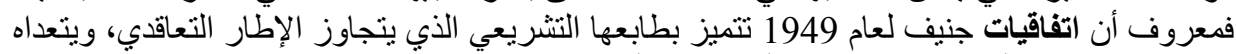

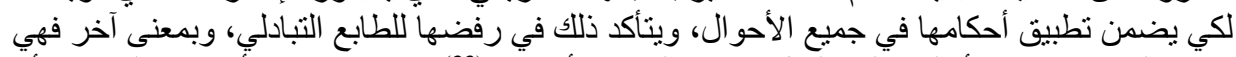

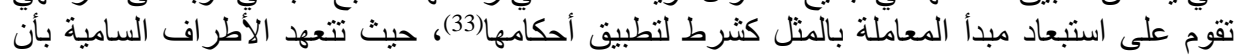

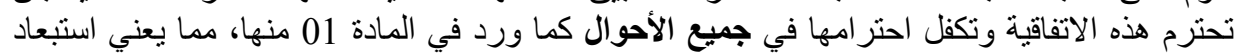

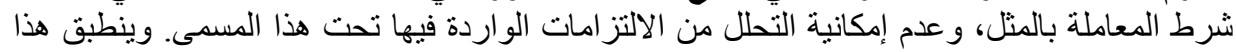

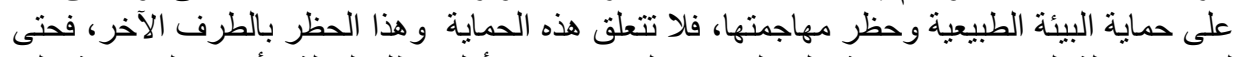

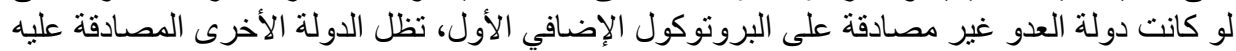
ملزمة بأحكامه و بأحكام مادتبه

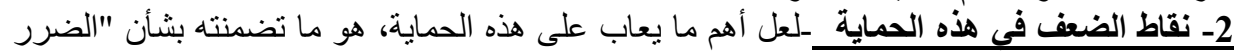

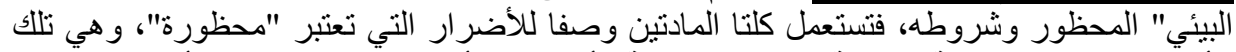

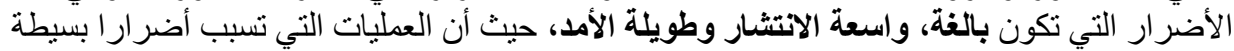

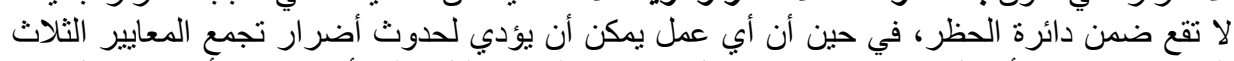

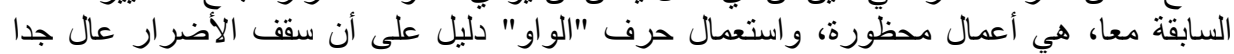

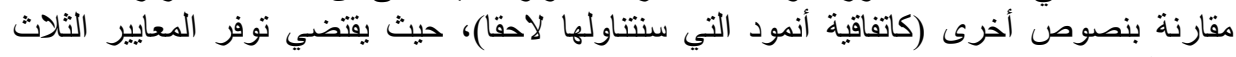

مجتمعة.

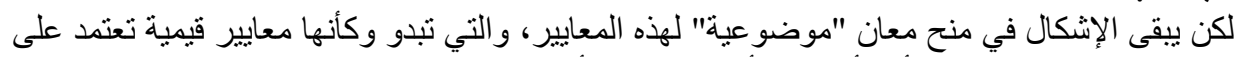

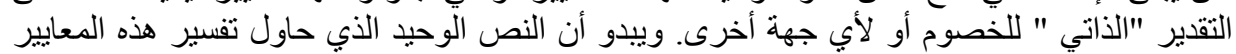

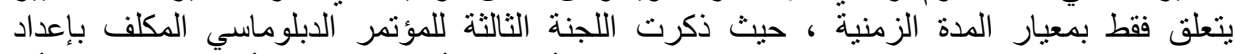

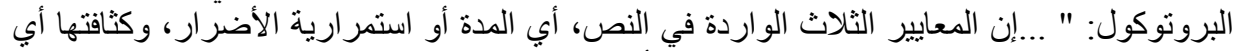

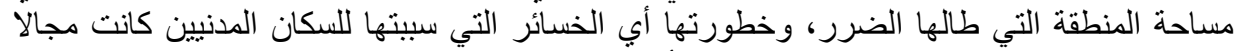

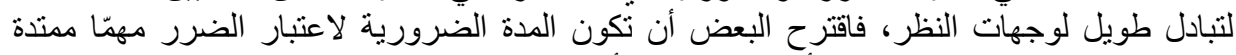

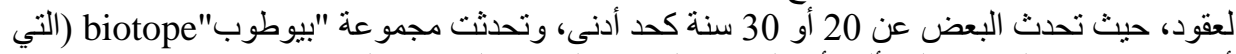

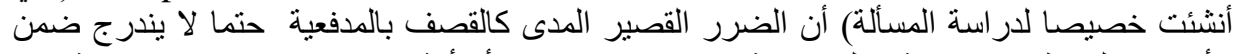

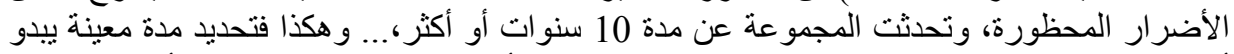

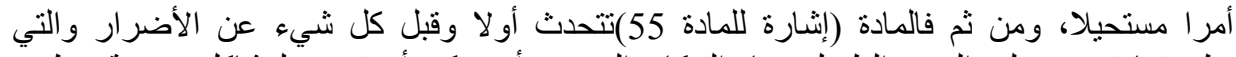

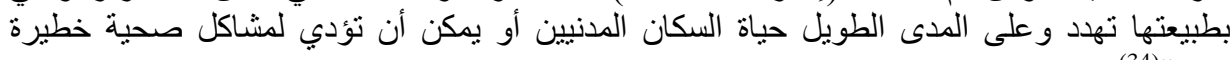

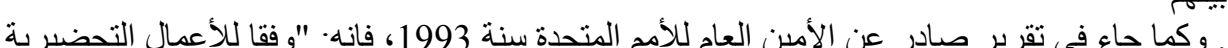

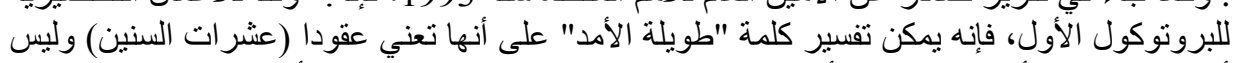

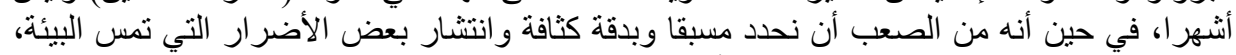

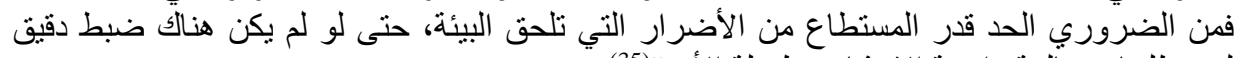

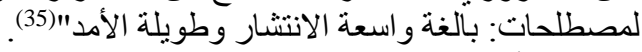

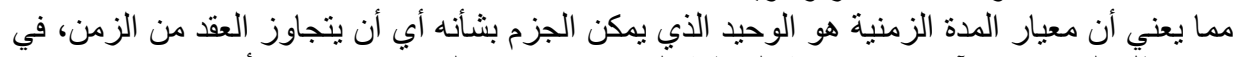

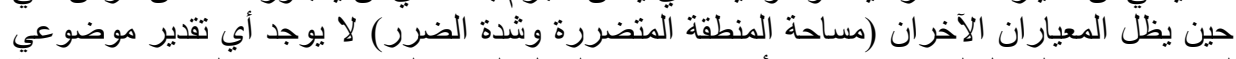

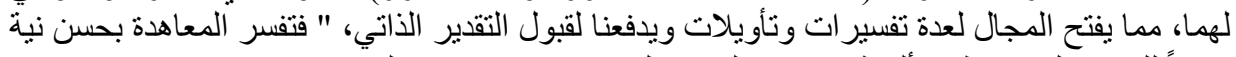

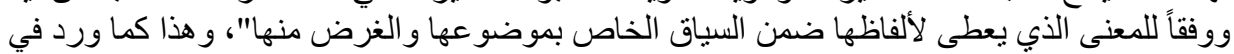

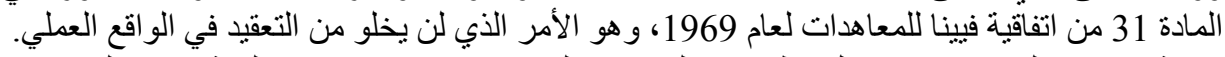

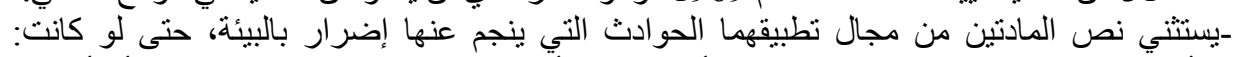
"الأضرار بالغة واسعة الانتشار وطويلة الأمد"، حيث أنهما تحظران فقط استخدام وسائل أو أساليب لئب 
قتال، يقصد بها أو يتوقع منها أن تلحق بالبيئة الطبيعية أضرارا ...فتستنىى الأضرار الناجمة عن حو ادث عرضية أو غير متو قاونة.

ـانحصار المجال المكاني للتطبيق: بالرجوع إلى نص المادة 49 الفقرة 02 من البروتوكول الأول،

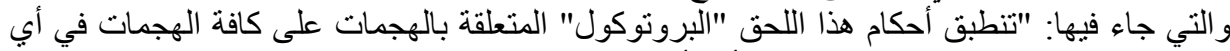

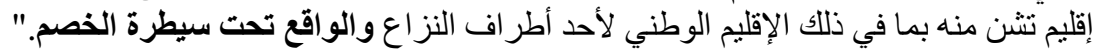

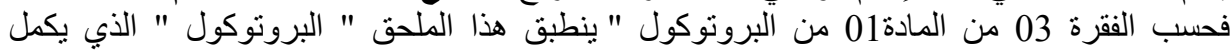

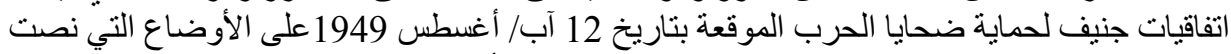

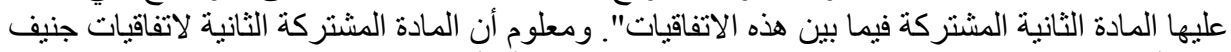

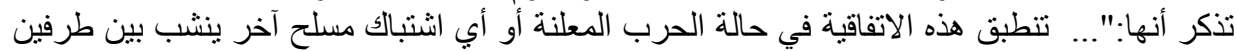

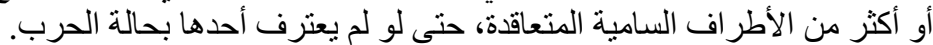

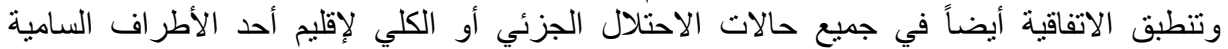

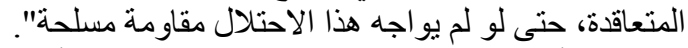

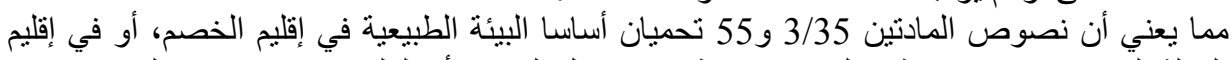

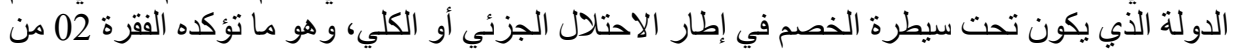

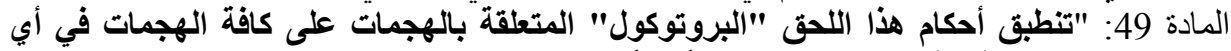

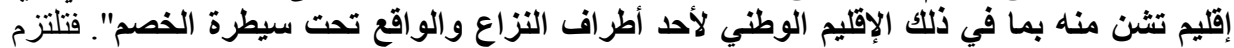

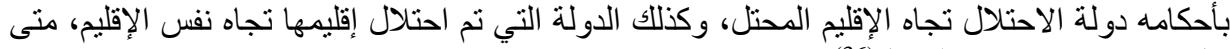

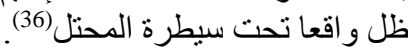

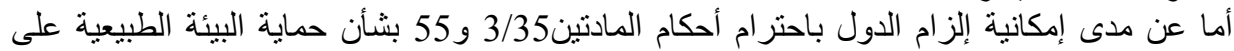

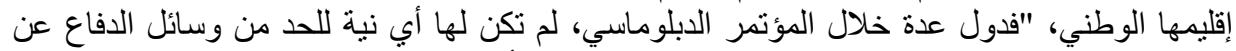

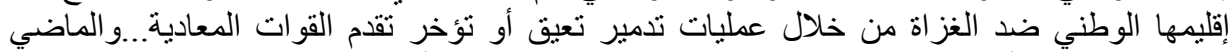

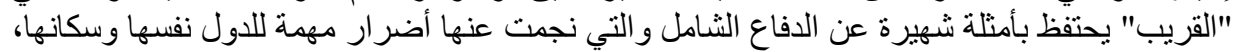

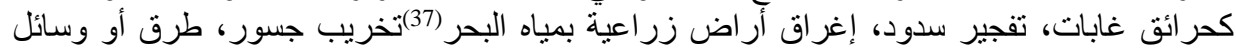
اتصال، مصانع، ورشات مخازن للمؤن الغذائية..." (38) . و هكذا فلا يوجد ما بلزم الدول التقبد بأحكام المادتين السابقتين في تعاملها مع "بيئتها الطبيعية"، فالتز امها

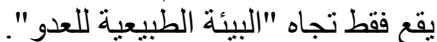

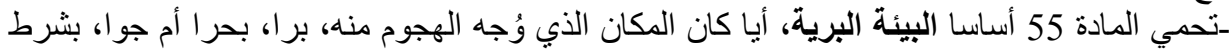

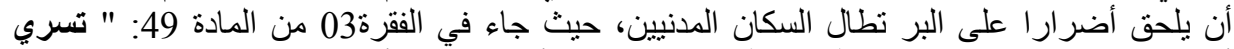

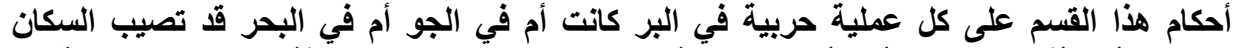

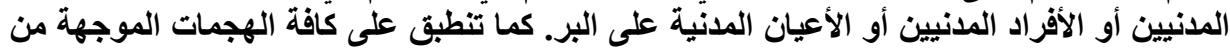

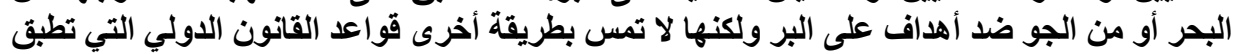

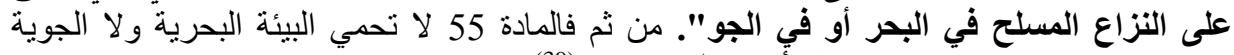

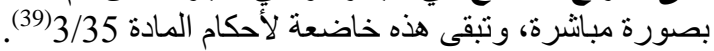

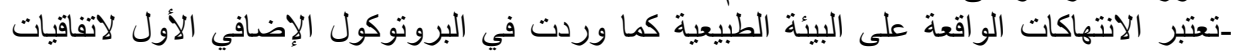

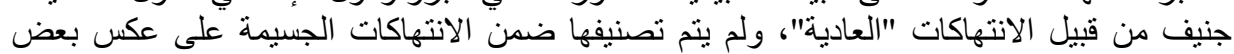

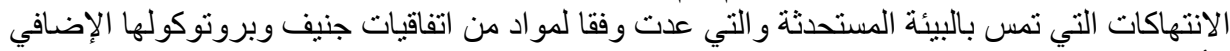

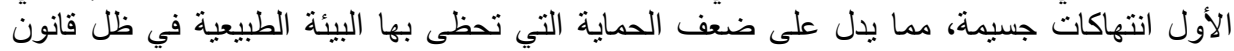

المطلب الثاني: الحماية من خلال اتفاقية إنمود

تم إصدار هذه المعاهدة كرد فعل عن العمليات التي كانت تقوم بهان القوان القوات الأمريكية في فيتنام و الهند

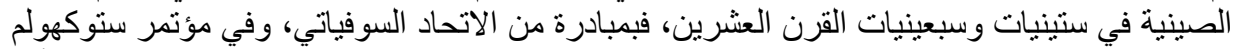
للبيئة عام 1972، تم اقتراح إدراج هذه النقطة للنقاش في برنامج عمل الدورة 29 للجمعية العامة للأمم 


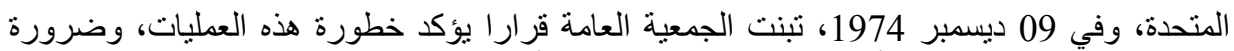

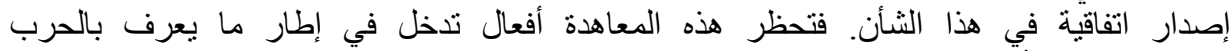
الجيوفيزيائية(40) أو الميزولوجية.

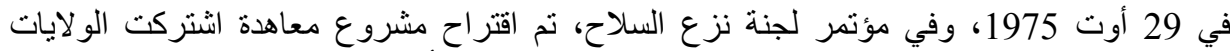

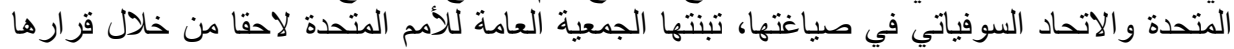

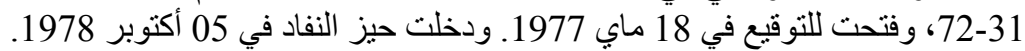

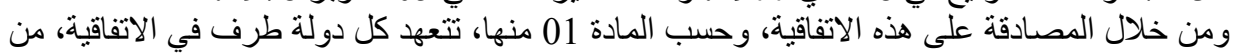

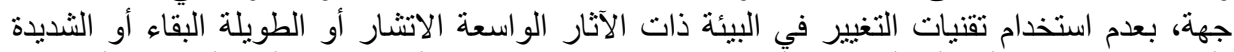

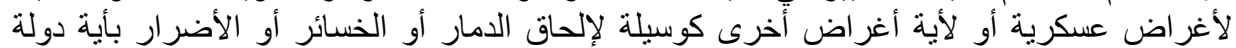

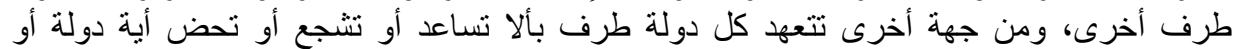

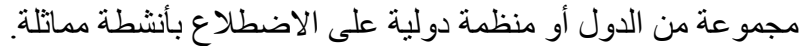

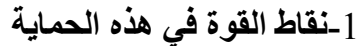

لعل أهم ما أتت به هذه الاتفاقية أنها لا تشترط لتطبيقها-على عكس البروتوكول الإضافي الأول-حدا

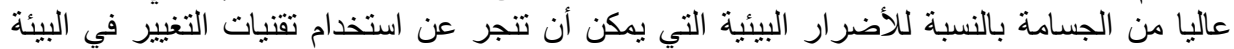

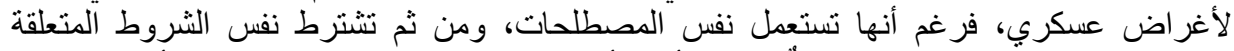

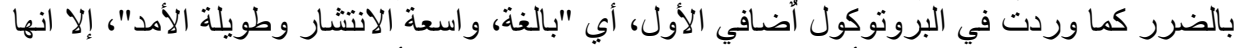

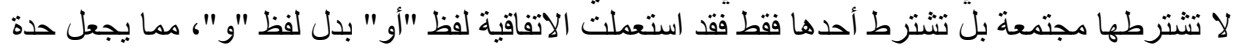
الأضر ار المطلوبة أقل وأخف، فتمنح بذلك اللك حماية أوسع.

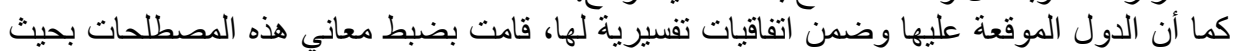

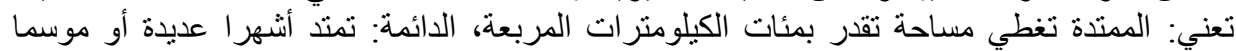

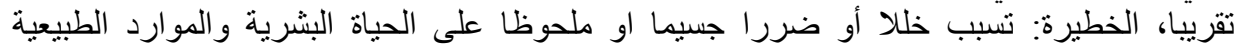

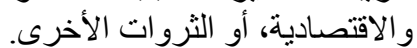

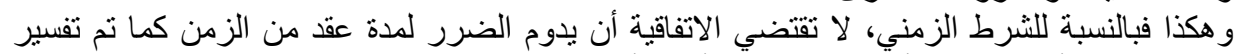
البروتوكول الأول، بل فقط أن يمند الضرر لأشهر أو موسم. 2-نقاط الضعف في هذه الحماية

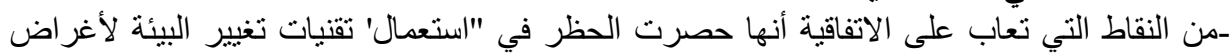

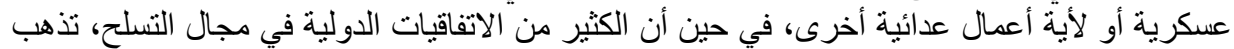

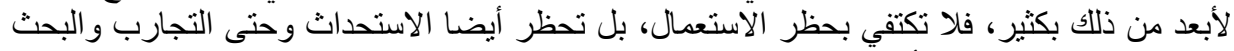

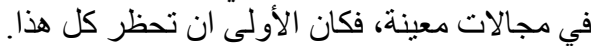

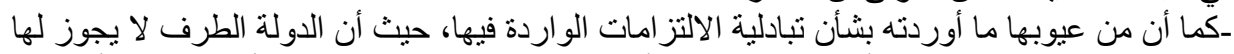

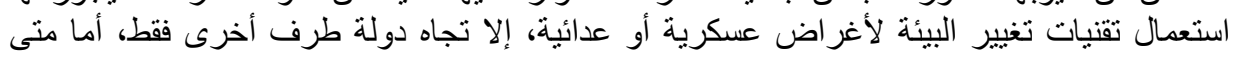

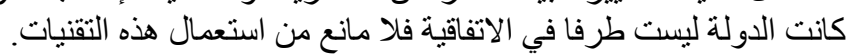

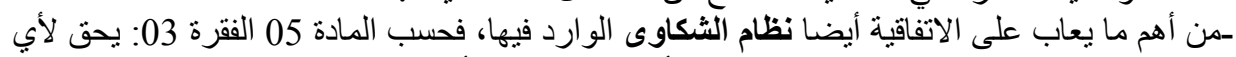

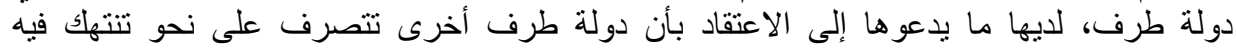

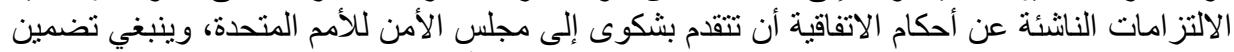

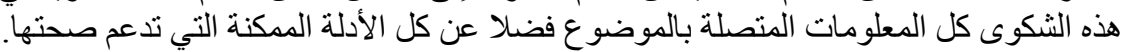

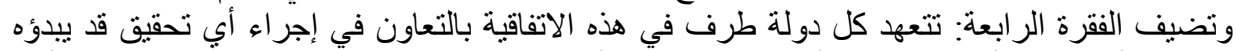

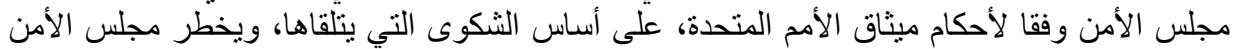
الدول الأطر اف بنتائج التحقيق.

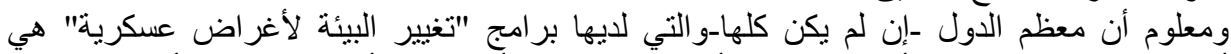

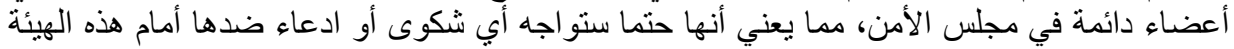


بحق النضض الذي سيحول دون إمكانية اتخاذ أي إجر اء ضدها، المر الذي يضعف الحماية كثير ا، ويجعل

لقد أسهم التطور التقني الكبير الذي عرفته البشرية منذ النصف الثاني من القرن العشرين في مضاعفة

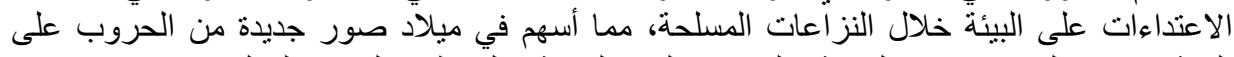

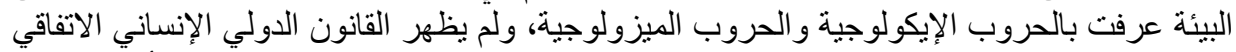

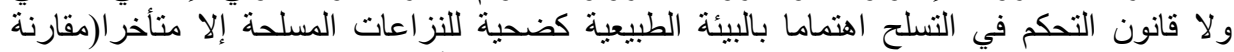

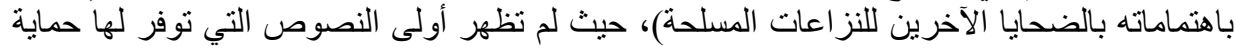

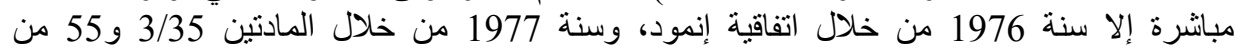

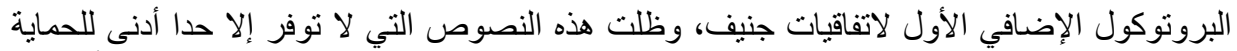

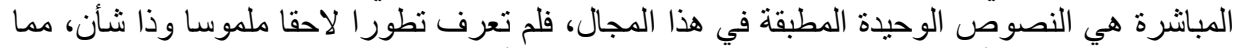
يجعلها قاصرة و لا تتأقلم بالثكل المطلوب مع ما استحدث من أساليب ووسائل قتال خطيرة على الئى البيئة.

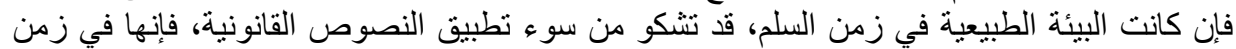
النزاع المسلح تشكو من نقص هذه النصوص وفن وفر اغ قانوني رهيب لا يز ال يحرمها من الحماية المبانشرة

(1)-David Zierler, The Invention of Ecocide: Agent Orange, Vietnam, and the Scientists who Changed the Way We Think about the Environment, University of Georgia Press, USA, 2011, p14.

(2)-Marie-hélène lavallard, « Une guerre chimique sans fin : l'agent orange au Vietnam », Recherches internationales, Laval, n 86, avril-juin 2009, p. 145

(3)- Marie-hélène lavallard,op.cit. pp 151-152.

(4)-Les graves dommages des guerres sur l'environnement, 22 novembre 2012, 16 h 59

: notre-planete.info,

http://www.notre-

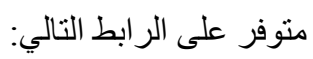

planete.info/actualites/actu_3548_guerre_environnement.php.

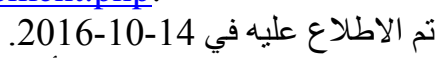

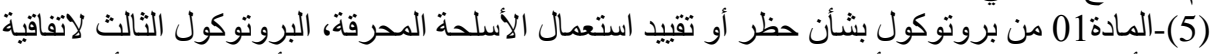

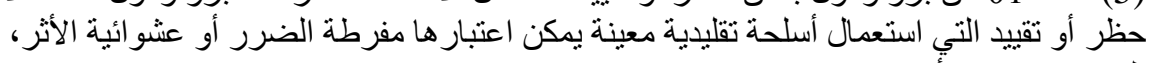

الصادرة في 10-أُكتوبر - 1980

(6)-عمر نسيل، أحكام أسلحة الدمار الثامل في الفقه الإسلامي والقانون الدولي الإنساني/ دراسة

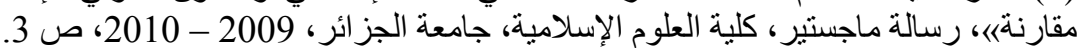

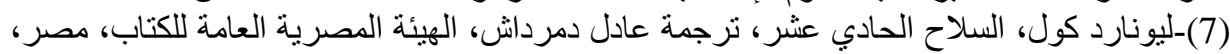

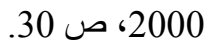

(8)- Steve Tulliu et Thomas Schmalberger, Les termes de la sécurité : un

lexique pour la maîtrise des armements, le désarmement et l'instauration de la confiance, UNIDIR Institut des Nations Unies pour la recherche sur le désarmement Genève, Suisse, Nations Unies, 2007, p.62. 
(9)-Santé publique et armes chimiques et biologiques, Rapport d'un groupe de consultants de l'OMS, Organisation Mondiale de la Santé, Genève, 1970, pp.58-60

http://apps.who.int/iris/bitstream/10665/62904/1/24209.pdf

$$
\text { منوفر على الموقع التالي لمنظمة الصحة العالمية: }
$$$$
\text { تم الاطلاع عليه في 30-09-2016. }
$$

$$
\text { الأولى، (10) أحمد السروري، مقدمة في كيمياء التلوث البيئي، دار الحامد للنشر و التوزيع، عمان،الطبعة }
$$

(11)-Steve Tulliu et Thomas Schmalberger , op.cit., pp.41-43.

$$
\begin{aligned}
& \text { (12)-محمد علي أحمد، الإرهاب البيولوجي (خطر داهم يهدد البشرية)، نهضة مصر للطباعة والنشر }
\end{aligned}
$$

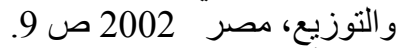

$$
\begin{aligned}
& \text { (13)-أحمد السروري، التلوث البيئي بالأسلحة والحروب الكيميائية و البيولوجية و النووية، دار الحامد، }
\end{aligned}
$$

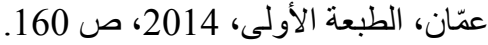

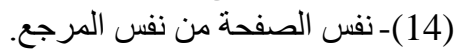

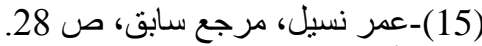

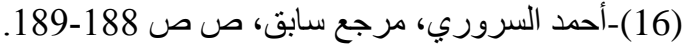

(17)- weather modification : altération intentionnelle, ou par inadvertance, des conditions météorologiques par l'action humaine. weather control : altération intentionnelle des conditions météorologiques par l'action humaine, avec comme condition supplémentaire que l'objectif de la modification est défini et les conséquences prévisibles.

Luc Mampaey, « Le programme HAARP, science ou désastre »,Rapport du Groupe de Recherche et d'Information sur la Paix et la Sécurité GRIP, Bruxelles, 04 mai 1998.p.04.

www.grip/fr/node/15.

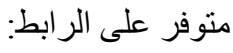

تم الاطلاع عليه في 15-18-2016.

(18)-Tamzy J.House, and Al,"Weather as force multiplier: Owning the weather in 1025", research paper presented to American Air Force, august 1996, p.21-22.

csat.au.af.mil/2025/volume3/vol3ch15.pdf

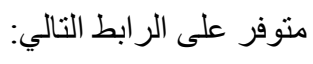

تم الاطلاع عليه في 15-08-2016. - ت ت

(19)- Ibid. , pp.5-6.

(20)- Luc Mampaey, Le Programme HAARP : science ou désastre ? ,Les

Rapports 98/5 du GRIP (GROUPE DE RECHERCHE ET D'INFORMATION

SUR LA PAIX ET LA SÉCURITÉ), novembre, 1998, 77 pages, 450 FB - 80

FF.

متوفر على الر ابط التالي: 
http://archive2.grip.org/bdg/pdf/g1688.pdf

(21)- « Une lecture attentive de la littérature de diverses sources américaines,discrètes mais néanmoins publiques, dont le Département de la Défense (DoD), la DARPA (Defense Advanced Research ProgrammeAgency), l'U.S. Air Force, l'U.S. Navy, l'U.S. Army War College, d'instituts de recherche tels que la RAND Corporation et le Woodrow Wilson Center, ou des firmes privées liéesaux programmes de recherche militaire, démontrent pourtant que les techniques de modification de l'environnement sont une préoccupation ancienne et permanente des Etats-Unis, mais qu'un regain d'intérêt pour ces techniques estnettement perceptible depuis le début des années 90 ».

Voir

(21)-Ibid, p.8.

(22)- Ibid.p.06.

(23)Tamzy J.House, and Al,op.cit., p.21-22.

(24)-Karine Mollard-Bannelier, La protection de l'environnement en temps de conflits armés, Edition A.Pedone, Paris, 2001, p..86

(25)-Projet d'articles sur la responsabilité de l'Etat pour fait internationalement illicite et commentaires relatifs, Texte adopté par la Commission à sa

cinquante-troisième session, en 2001, et soumis à l'Assemblée générale dans le cadre de son rapport sur les travaux de ladite session. ACDI, vol. II(2), , 2001, p.208

(26)- Karine Mollard-Bannelier, op.cit., p..87

$$
\begin{aligned}
& \text { (27)-حيث تذكر المادة الهـادة 36من البروتوكول الأول ، والو اردة تحت عنوان: الأسلحة الجديدة }
\end{aligned}
$$

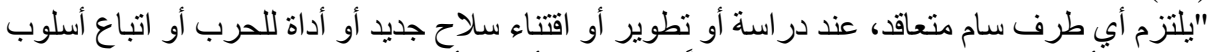

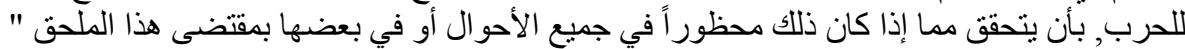

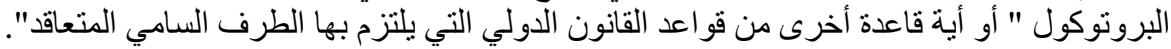

(28)- « Les attaques contre l'environnement naturel à titre de représailles sont interdites. "

(29)-“Attacks against the natural environment by way of reprisals are prohibited»

$$
\begin{aligned}
& \text { (30)- نجاة أحمد أحمد إبراهيم، المسؤولية الدولية عن انتهاكات قواعد القانون الدولي الإنساني، منشأة }
\end{aligned}
$$

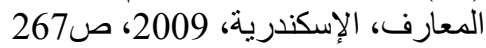

$$
\begin{aligned}
& \text { (31)- محمد بهاء الدين باثنات، المعاملة بالمثل في القانون العانية الدولي الجنائي_الأعمال الانتقامية وفكرة }
\end{aligned}
$$

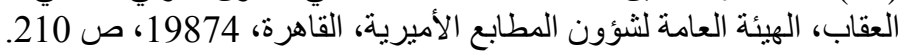

$$
\begin{aligned}
& \text { (33)-صلاح جبير البصيصي ، دور محكمة العدل الدولية في تطوير مبادئ القانون الدولي الإنساني، }
\end{aligned}
$$

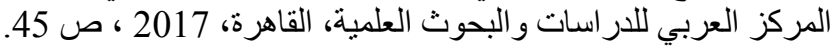

(34)-Actes de la Conférence diplomatique sur la réaffirmation et le développement du droit international humanitaire applicable dans les conflits armés, Genève, 1974-1977, Vol.VI, CDDH/SR.39, p.113. 
(35)- Rapport du secrétaire général sur la protection de l'environnement en période des conflits armés, A/48/269, 29 juillet 1993, pp.7-8.

(36)- David Cumin, Manuel de droit de la guerre, Groupe Larcier, Bruxelles, 2014, p274.

$$
\text { (37)- على غر ار ما قامت به هولندا خلال الحرب العالمية الثانية. }
$$

(38)-Claude Pilloud, Yves Sandoz, Christophe Swinarski, Bruno

Zimmermann, Jean S Pictet, Commentaire des protocoles additionnels du 8 juin 1977 aux Conventions de Genève du 12 août 1949, Martinus Nijhoff

Publishers, Dordrecht, 1986, pp.675-676.

$$
\text { ومن أمثلة ذلك ما قامت به الصبن عام 1938من تفجير سد مائي لمنع تقدم القوات اليابانية. }
$$

(39)-David Cumin, op.cit., p274.

(40)- Claude Pilloud, op.cit., p.422.

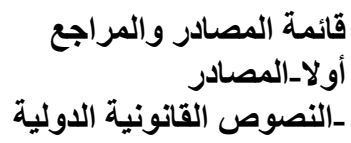

ـاتفاقية حظر استخدام تقنيات التغيير في البيئة لأغر اض عسكرية أو لأية أغر اض عدائية أخرى،

$$
\text { 10ديسمبر 1976، من قبل الجمعية العامة للأمم المتحدة، وتم فتح باب التوقيعات في } 1877
$$

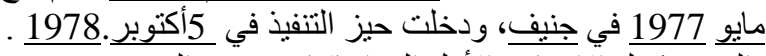

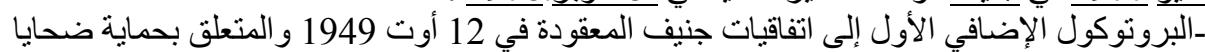

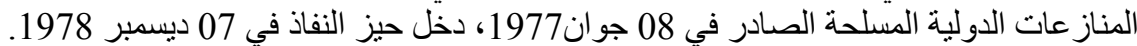

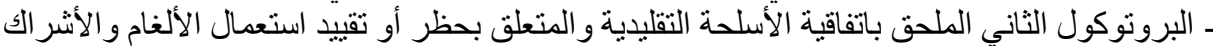

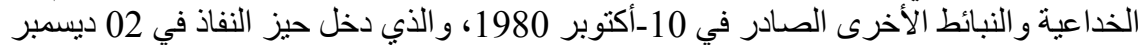

1983، و المعدل في 03 ماي 1996، و الذي دخل حيز النفاذ ـحسب النسخة المعدلة_ في 03 ديسمبر

1998

ــ البروتوكول الثالث لاتفاقية حظر أو تقيبد استعمال أسلحة تقليدية معينة يمكن اعتبار ها مفرطة الضرر

أو عشو ائية الأثر ، الصادر في 10-أكتوبر -1980، و الذي دخل حيز النئ النفاذ في 02 ديسمبر 1983.

ـأحمد السروري، مقدمة في كيمياء التلوث البيئي، دار الحامد للنشر والتوزيع، عمان،الطبعة الأولى،

ـصلاح جبير البصيصي، دور محكمة العدل الدولية في تطوير مبادئ القانون الدولي الإنساني، الركز

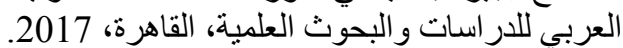
-ليونارد كول، السلاح الحادي عشر، ترجمة عادل دمرداش، الهيئة المصرية العامة للكتاب، مصر، 2000

ــمحد بهاء الدين باثات، المعاملة بالمثل في القانون الدولي الجنائي_الأعمال الانتقامية وفكرة العقاب،

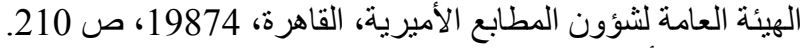
ـ محمد علي أحمد، الإر هاب البيولوجي (خطر دالأهم يهدة البشرية)، نهضة مصر للطباعة والنشر

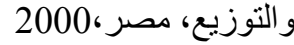




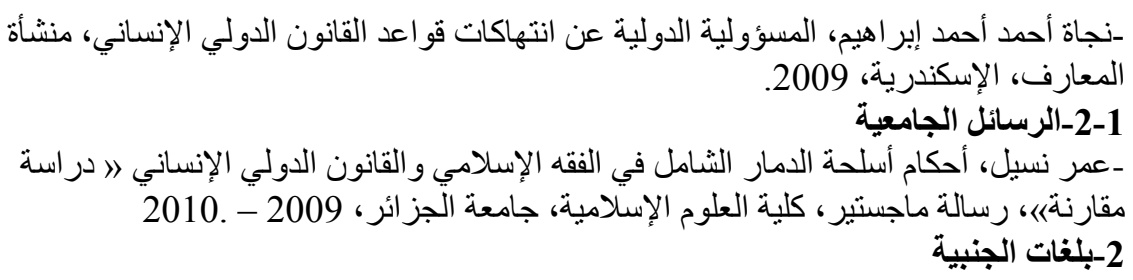

\section{2-1-Ouvrages}

-Claude Pilloud, Yves Sandoz, Christophe Swinarski, Bruno

Zimmermann, Jean S Pictet, Commentaire des protocoles additionnels du 8 juin 1977 aux Conventions de Genève du 12 août 1949, Martinus Nijhoff

Publishers, Dordrecht, 1986

- David Cumin, Manuel de droit de la guerre, Groupe Larcier, Bruxelles, 2014.

-David Zierler, The Invention of Ecocide: Agent Orange, Vietnam, and the

Scientists who Changed the Way We Think about the Environment, University of Georgia Press, USA, 2011.

-Karine Mollard-Bannelier, La protection de l'environnement en temps de conflits armés, Edition A.Pedone, Paris, 2001

\section{2-2-Articles}

-Marie-hélène lavallard, « Une guerre chimique sans fin : l'agent orange au Vietnam », Recherches internationales, Laval, n 86, avril-juin 2009.

\section{2-3-Textes internationaux}

-Actes de la Conférence diplomatique sur la réaffirmation et le développement du droit international humanitaire applicable dans les conflits armés, Genève, 1974-1977, Vol.VI, CDDH/SR.39, p.113.

- Rapport du secrétaire général sur la protection de l'environnement en période des conflits armés, A/48/269, 29 juillet 1993.

- Projet d'articles sur la responsabilité de l'Etat pour fait internationalement illicite et commentaires relatifs, Texte adopté par la Commission à sa cinquante-troisième session, en 2001, et soumis à l'Assemblée générale dans le cadre de son rapport sur les travaux de ladite session. ACDI, vol. II(2), , 2001.

-www.notre-planete.info

-www.grip.org

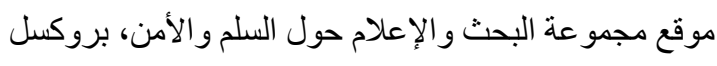

-www.who.org 